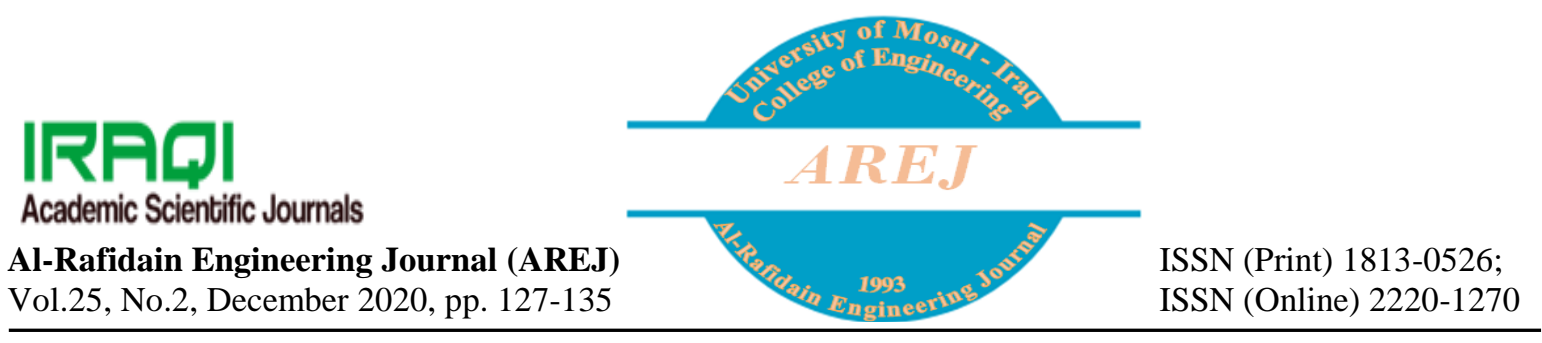

\title{
Design of an Efficient Network Monitoring System Based on Agents
}

\author{
Ahmed Mohammed Basheer* \\ ahmed.basheer@uoninevah.edu.iq \\ Turkan Ahmed Khaleel ${ }^{* *}$ \\ turkan@uomosul.edu.iq \\ * Electronics Engineering Collage, University of Ninevah \\ ** Computer Engineering Department, Collage of Engineering, University of Mosul
}

Received: $1 / 3 / 2020$

Accepted: 10/7/2020

\begin{abstract}
In this paper, a network service monitoring system was proposed by relying on the agent for several reasons, including the possibility of providing effective control over the network, preventing penetration, reducing complications, ensuring the continuity of service on the network, permitting quality of service, reducing downtime and system cost. The proposed network management and monitoring system includes a set of tasks such as (monitoring the network service using a simple interface, the ability to add and delete new users, provide security, and the ability to distribute monitoring tasks to many agents and make adjustments independently without user intervention). The proposed monitoring system can be applied to the internet or local networks. The agent monitors and observes events on the network and collects information from all parts of the network and sends it to the server to convert it to a page that is designed to display this information in real-time to the administrator. Event monitoring information on the network is collected at the user's request or on a scheduling system created by the network manager and sent this information to the server to alert the manager when a fault occurs. By providing the ability to make some decisions without consulting the manager. This system has been designed to be general in all types of networks in the sense that it can be used in monitored and manage the network activated or passive, and it can be applied in the local networks and global networks.
\end{abstract}

Keywords:

Agent; Monitor System; Network service; Network Management; Quality of service.

https://rengj.mosuljournals.com

Email: alrafidain_engjournal1@uomosul.edu.iq

\section{INTRODUCTION}

Through the past several years and until today, the computer industry has been passed through big development, and become the connection between computers a major challenge. A simple workplace consists of several computers, printers, and servers connected, and can be connected to the personal computer at home by creating a communications and transport network to make the work more comfortable. Because of the development of technologies, it has become possible to connected a large number of devices in multiple networks together instead of a few computers. However, the complexity and size of the network become a major challenge and requires a good network monitoring and management system, so the demand for monitoring and management system has become urgent [1].

The world today is dependent on information technology. To facilitate the exchange of information and communication, the data networks play a key role in providing many services, Although they use different types of networks based on different technologies. The treatment with information, news, multimedia, and sensitive data such as bank details, financial and accounting details for companies in government and private sector. therefore Data networks must be reliable by users and continue to be given services under any conditions encountered by networks such as having a heavy load on the network. [2]. The network monitoring system enables network engineers and 
administrators to remotely monitor network statistics. The monitoring system allows administrators to remotely monitor networks and use any device that is connected to the network to access. This is one of the main objectives in developing the observable systems to enable access from anywhere in the world. The system tracks network devices, servers, nodes, connectivity, traffic as well as basic hardware configurations [3]. The traditional network management and monitoring systems perform management tasks in a centralized way[4]. This centralized management results in a scalability problem because the network management center is responsible for collecting and processing all the monitoring data from all the network elements being managed, this will create a delay in the system and add traffic load on the network [5].

One of the important tasks to the system's administrator is monitoring networks to ensure proper system operation and protect system resources from being misused by intruders or attackers. This typically involves monitoring for inconsistencies in user activities, resource usage, system configuration, traffic load, and enforcing security policies. A large enterprise network typically consists of hundreds of nodes and resources with varying amounts of heterogeneity among them in terms of the hardware and software [6].

So one of the most important parts of network management is a monitoring system capable of monitoring and tracking many sites, networks, and tasks in real-time.[7] The collected monitoring information is also necessary to develop the services required to the highest level, and to develop the components of the network system that provide decision support, Ultimately, some degree of automated decision-making, to help maintain and improve workflow through the network [8].

The term network management is divided into network monitoring and network control by using programs or devices, where monitoring is responsible for test the communication process between devices on the network, examining hostile activities, and other tasks [4].

This operation goal of providing an efficient and high-performance network. Several of the literature related to research has been reviewed over the past twenty years and to identify and benefit from the most important work that researchers have done and avoided errors that have occurred with them.

Several remote monitoring and control programs and systems have been viewed. Whether these systems are commercial products or experimental research platforms only. The researches related to the monitoring systems that were conducted were classified into the following categories:

- Internet monitoring using proxies, GPS, etc.[9].

- Monitor using a wireless sensor[9].

- Wireless monitoring using Bluetooth or Wi-Fi [9].

- GSM-SMS protocols that use the GSM module individually or with Internet technologies[9].

(Blaauwbroek et. al., 2018) designed a distributed monitoring system for energy production and distribution networks, reducing consumption and monitoring power transmission lines [10]. (Monasa et al, 2016) In this paper a network screen is designed on conventional computers, enabling it to perform smart processors to handle loads load well while developing a mechanism that supports SystemOn-Board (SOB) [11]. (Chen et. Al, 2016) have developed a reliable and robust system to monitor and detect threats to efficiently mitigate cyber threats [12]. (Zhong et. Al., 2010) They designed a GPRS-based wireless remote monitoring system[13]. (Kumari and Malleswaran, 2010) They developed a real-time equipment monitoring and control system using built-in web-based technology that connects the device directly to the network as a point of contact [14].

The commonly agreed benefits of an agent have been discussed in many research papers [15][16][17]. From this benefits increase the flexibility of the system by easy access to the resources hosted by the server and can be used to extend and update dynamically capability of application, reduce the network traffic, asynchronous interaction it can execute the distributed task, interaction with real-time system and support dor heterogeneous environment.

In this paper, agents technology was used to design the network monitoring system and provide the best services. In addition to this introduction, this paper contains five other sections: Section 2 presents the design of the monitoring system. Section 3 presents the monitoring system based on the implementation of the agents. Section 4 presents results and discussions. Section 5 Conclusions and some future work.

\section{MONITORING SYSTEM DESIGN}

Network monitoring and management system carries problems related to configuration capability, reliability, efficiency, security, and ability to count surrounding and distributed 
accounts, and controlling the network to ensure the smooth operation of the network [18]

In this paper, a monitoring system is designed to respond to all the requirements of the current monitoring systems in use, as well as the flexibility to distribute management and monitoring functions over several nodes and send information to the server to be displayed to management or to alert the manager when a network failure occurs, after which the manager takes action Appropriate measures or the assignment of an agent to carry out appropriate actions.

This system also allows flexibility in displaying information that is prepared for management, i.e. the important choice or need to be monitored for display, unnecessary blocking, and simple graphical interfaces designed by the designer, as well as the ability to display this information from any computer or mobile on the network. To protect the system from intrusion, we designed an entry authentication interface

\subsection{System Architecture}

The physical architecture of the system is as shown in Figure 1, consisting of a group of computers connected to the central system management station, the server, which hosts the central control agent. The server also provides an interface for human service operators to interact with the system and perform administrative functions such as system configuration, maintenance, updates, service separation, modifying some settings, etc.

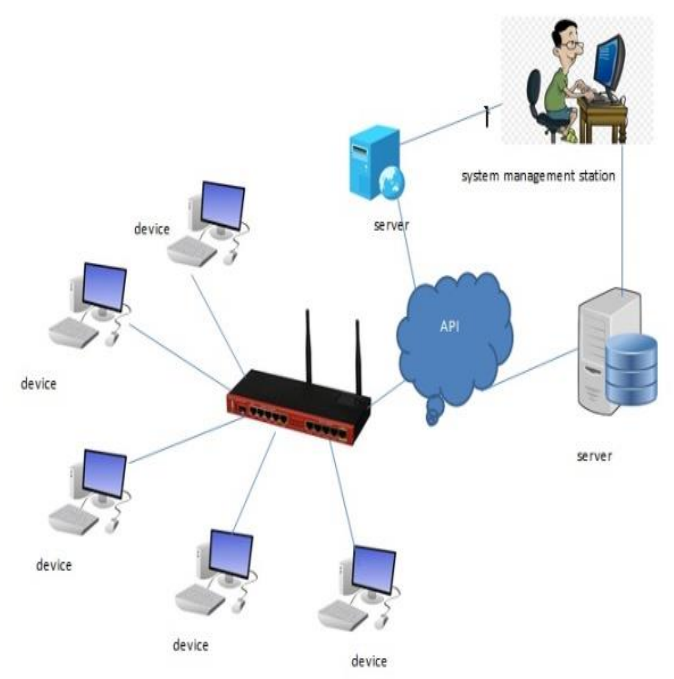

Figure1: Physical Architecture

To design the server interface the PHP programming language which is used to develop Internet sites with a range of other languages such as HTML and CSS is used to configure and format display interfaces and is linked to the application software interface (API), through the designed interface, Which is the link between the system and the router board [19]. As shown in Figure 2.

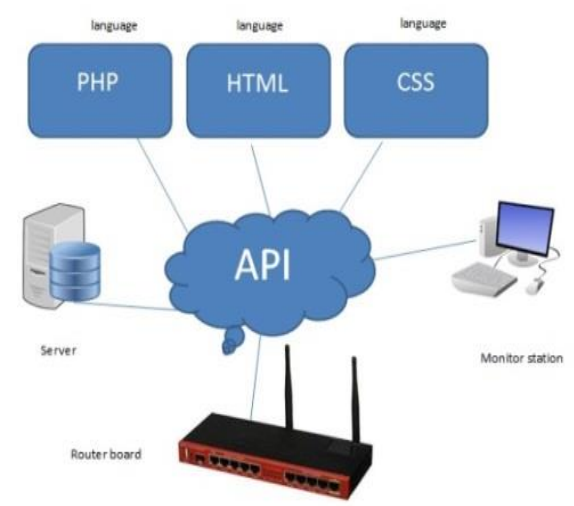

Figure 2: Software architecture

\subsection{Network Communication System Design}

After linking the network components to the router board we write the Class API which contains several functions. The most important of which is the interconnection between the router board and the server to get the information reading by the router board and convert it from matrices to specific tables that are designed as we needed or desired by the manager (Required to be monitored) thus information is displayed regularly, including these functions (Connect, Write, COMM).

This functionality is called by the software to perform a set of code written in any language. this research uses the PHP programming language is one of the most popular programming languages used to create and develop websites, applications and is one of the languages that the webserver interprets and implements its code and then sends the result to be displayed in the user's browser.

The PHP language is used to create dynamic web pages any variable page content that changes as a result of user interaction and because of the interactive capabilities of this language with web pages and the user, type of control from web pages has been added directly by the observer and this allows control of the network from any device on the network.

For security purposes, an entry system is designed to protect the network from intrusion so that the person authorized to enter the network is given a username and password, The scheduling of some functions was also used by the designer and as needed to carry out certain tasks during the 
specified periods without returning to the manager to make monitoring and management more accurate, intelligent and easier.

\subsection{Agents Functional Description}

In this paper, the network monitoring system is designed based on a group of Agents. The functions of all agents required in this system have been defined to collect data, process it, or control and make decisions when necessary. All Agents are designed and programmed on the server-side. After connecting the network components to the routing board, the Class API has been written, which contains many functions, the most important of which is the interconnection between the routing board and the server to obtain information. Read through the routing plate and convert it from a matrix to specific tables, this is designed as needed or as desired by the manager (required to be monitored) This information is displayed regularly, including these functions (Connect, Write, COMM). The PHP document web site has been connected to a database with a "config.PHP" file.

\subsection{Agents Interface Design}

In this section we outline the main work plan, which consists of two parts with some options and functions as shown in Figure (3) and (4) :

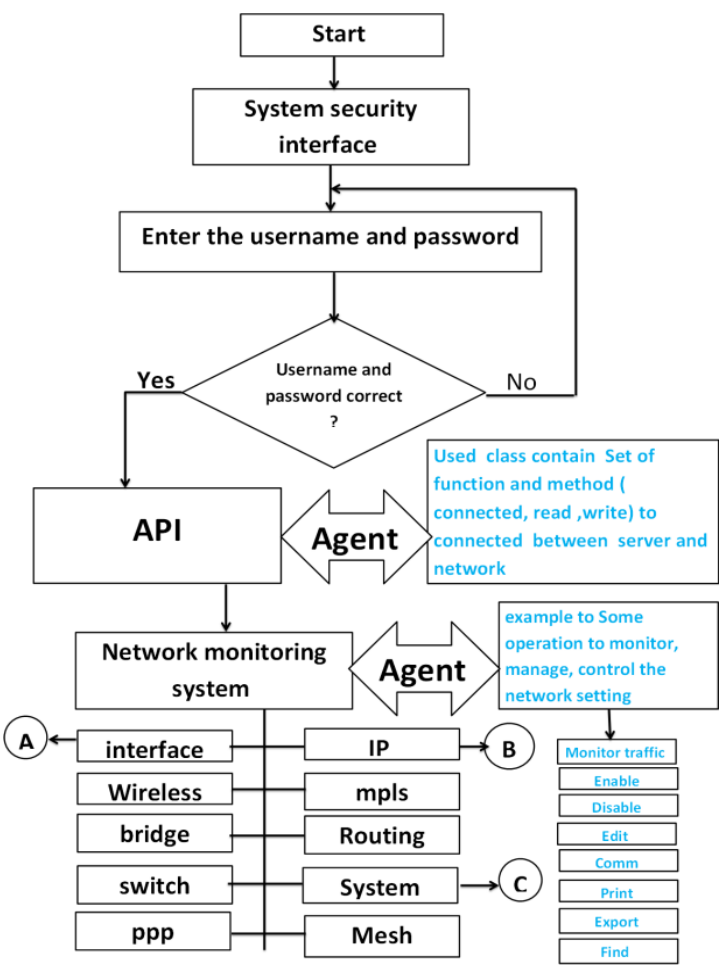

Figure 3: Main Menu of System

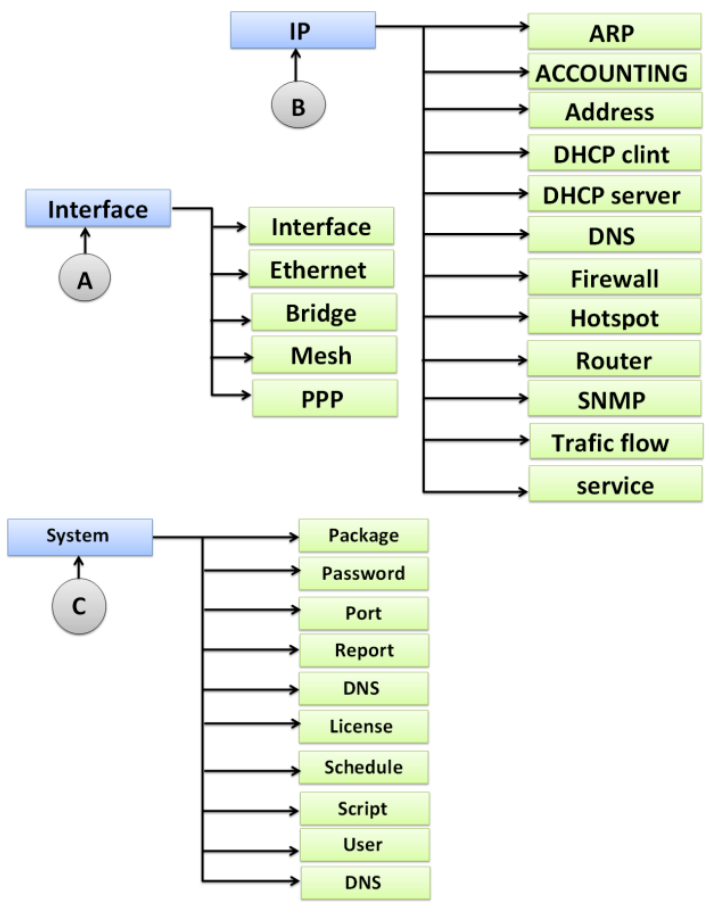

Figure 4: Sub Menus of System

\subsection{Monitoring System Implementation}

After completion of the network connection process. The administrator enters to system from the page address given to him by the designer upon entering. This address asks the administrator to enter the name and password for security purposes and to verify the identity of the person authorized to enter the system. The system interface which contains many tabulations is then accessed with each tab containing information brought to from the network to display it on this page. After that, the system automatically connects with the network and fetches the interface information by Agent and sends these readings to the server. The server is linked to the network by the API. Where it is called by the software to make the linking to sending and receiving of information.

\section{RESULTS AND DISCUSSIONS}

This section deals with a set of interfaces for this system which was designed using Agents technology. Figure (5) shows the first interface to enter the system. This interface allows only authorized users to enter the network monitoring system as shown in Figure (6). And using monitoring system options, whether from collecting information about the devices connected to the network or controlling them. 


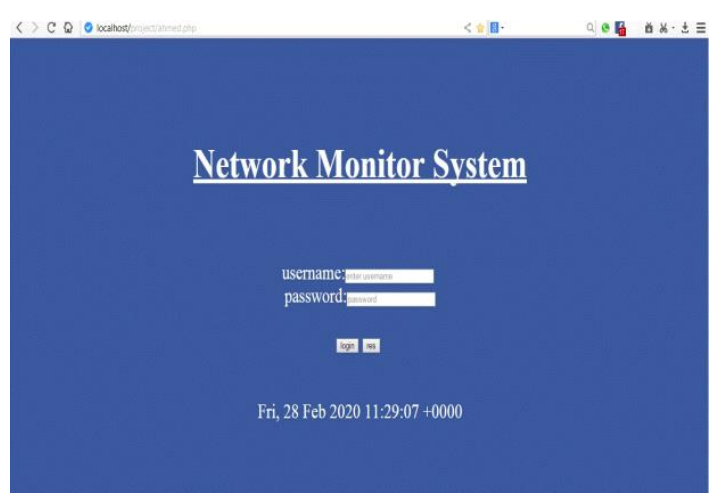

Figure 5: System access interface

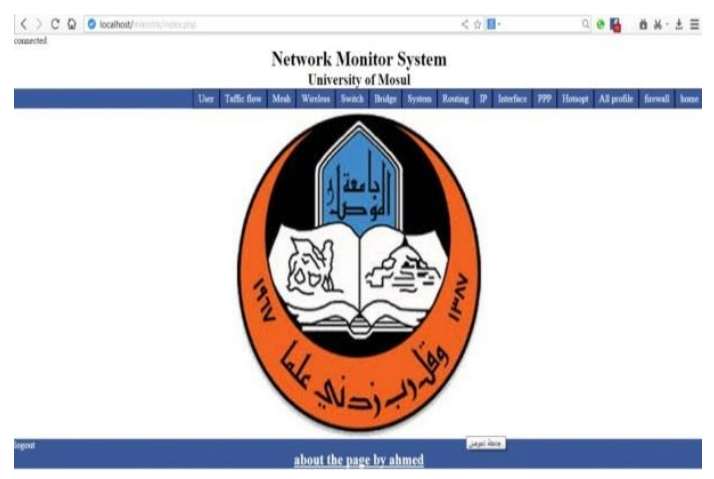

Figure 6: Network Monitoring system interface

The system interface consists of a set of options that allow the administrator to monitor and control the network and system, as shown in Figure(7).

As shown in Figure (8), the network monitoring system displays the router board interface information, learn about active and closed Ethernet, and control the router board from the system interface. Network users' information, username, password, address, packet size, data transfer speed, sending speed, receiving speed, traffic monitoring, status, and control.

In this paper, some important and required features have been chosen in modern monitoring systems. To test the availability of these features in the proposed system and compare them with a set of network monitoring programs and tools as shown in the following table (1):

The percentage of each network monitoring application is calculated based on the data in Table 1 where the number (1) is given if the system has this feature and number $(0)$ if this missing, and the percentage of each application has been calculated.
Percent $=$ (number of properties in the system/number of total properties) $* 100 \%$

The proposed system has some characteristics, including:

1- use a Web Browsers Interface. Results are sent from the server to a Web page that can be accessed from anywhere by knowing only its address.

2- depended on the agent to design and operate the system.

3- Remote access to the system which makes it easy to access the system from anywhere on the network using a computer or any mobile device.

4- A key feature of this system is to link the server agent to the Mikrotik and take advantage of all the microtecs that control the network.

From Table No. (1), we note that the proposed network monitoring system in our study has a big rating with $80 \%$ because of the features as shown in Figure (9) then the Dude and Solarwind with rate $65 \%$, followed by advance IP Scanner and Network Monitor Microsoft at 50\%.

\section{CONCLUSION}

The purpose of designing this system was the need for a system to manage and monitor network services that can be used by an ordinary person and the ability to alarm the network manager when any error happened by sending messages to phone or email and the ability to alarm the network manager when any error happened by sending messages to phone or email. Through this system, it is possible to diagnose problems that the network may be exposed to. This system provides the ability to control the continuity of network services which makes the system dynamic enough to respond to the changing environment. The benefits of this system can be summarized in the following:

- Maintain continuity and network ready.

- Ensure continuity of service by collecting information about network use.

- Detection Facilitates network error detection.

- Maintenance Facilitate network maintenance by monitoring the administrator and alerting him when it occurs.

- Cost control so that the user's needs are met at an affordable cost. 
Network Monitor System

University of Mousl Local Network Monitoring

\begin{tabular}{|c|c|c|c|c|c|c|c|c|c|c|c|}
\hline Address & Network & Interface & Actual-interface & Invalid & Dynamic & Disabled & RX multicast & TX multicast & Status & Modify & \begin{tabular}{|l|} 
Control \\
\end{tabular} \\
\hline ether1-gateway & E4:8D:8C:1A:3E:CD & $100 \mathrm{Mbps}$ & unlimited/unlimited & off & off & 0 & 0 & 0 & Open & Edit & Close \\
\hline ether2 & E4:8D:8C:1A:3E:CE & $100 \mathrm{Mbps}$ & unlimited/unlimited & off & off & $\sqrt{0}$ & 0 & 0 & Open & Edit & Close \\
\hline ether3 & E4:8D:8C:1A:3E:CF & $100 \mathrm{Mbps}$ & unlimited/unlimited & off & off & 0 & 0 & 0 & Open & Edit & Close \\
\hline ether4 & E4:8D:8C:1A:3E:D0 & $100 \mathrm{Mbps}$ & unlimited/unlimited & off & off & 682 & 472 & 372 & Open & Edit & Close \\
\hline ether5 & E4:8D:8C:1A:3E:D1 & $100 \mathrm{Mbps}$ & unlimited/unlimited & off & off & 0 & 0 & 0 & Open & Edit & Close \\
\hline ether6-master-local & E4:8D:8C:1A:3E:D2 & $100 \mathrm{Mbps}$ & unlimited/unlimited & off & off & 0 & 0 & 0 & Open & Edit & Close \\
\hline ether7-slave-local & E4:8D:8C:1A:3E:D3 & $100 \mathrm{Mbps}$ & unlimited/unlimited & off & off & 0 & 0 & 0 & Open & Edit & Close \\
\hline ether8-slave-local & E4:8D:8C:1A:3E:D4 & $100 \mathrm{Mbps}$ & unlimited/unlimited & off & off & 0 & 0 & 0 & Open & Edit & Close \\
\hline ether9-slave-local & E4:8D:8C:1A:3E:D5 & $100 \mathrm{Mbps}$ & unlimited/unlimited & off & off & 0 & 0 & 0 & Open & Edit & Close \\
\hline ether10-slave-local & E4:8D:8C:1A:3E:D6 & $100 \mathrm{Mbps}$ & unlimited/unlimited & off & off & 0 & 0 & 0 & Open & Edit & Close \\
\hline sfp1 & E4:8D:8C:1A:3E:CC & $1 \mathrm{Gbps}$ & unlimited/unlimited & off & off & 0 & 0 & 0 & Open & Edit & Close \\
\hline
\end{tabular}

Figure 7: System access interface

Network Monitor System

University of Mosul Local Network Monitoring

\begin{tabular}{|c|c|c|c|c|c|c|c|c|c|c|c|c|}
\hline \begin{tabular}{|l|} 
Name \\
\end{tabular} & \begin{tabular}{|l|} 
Service \\
\end{tabular} & Caller-id & Password & Profile & Routes & Limit-bytes-in & limit-bytes-out & last-logged-out & Disabled & Status & Modify & Control \\
\hline ppp2 & any & & 1111 & default & & 0 & 0 & $\mathrm{jan} / 01 / 1970$ 00:00:00 & false & Open & Edit & Close \\
\hline ppp3 & any & & 444444 & default & & 0 & 0 & $\mathrm{jan} / 01 / 197000: 00: 00$ & false & Open & Edit & Close \\
\hline ppp1 & any & & 12345 & default & & 0 & 0 & $\mathrm{jan} / 01 / 197000: 00: 00$ & true & Close & Edit & Open \\
\hline ppp4 & any & & ererer & default & & 0 & 0 & $\mathrm{jan} / 01 / 197000: 00: 00$ & false & Open & Edit & Close \\
\hline ppp5 & any & & $\operatorname{csccc}$ & default & & 0 & 0 & $\mathrm{jan} / 01 / 197000: 00: 00$ & false & Open & Edit & Close \\
\hline ppp6 & any & & & default & & 0 & 0 & $\operatorname{jan} / 01 / 1970$ 00:00:00 & false & Open & Edit & Close \\
\hline ppp7 & any & & & default & & 0 & 0 & $\mathrm{jan} / 01 / 197000: 00: 00$ & false & Open & Edit & Close \\
\hline ppp8 & any & & & default & & 0 & 0 & jan/01/1970 00:00:00 & false & Open & Edit & Close \\
\hline ppp9 & any & & & default & & 0 & 0 & $\mathrm{jan} / 01 / 197000: 00: 00$ & false & Open & Edit & Close \\
\hline ppp10 & any & & & default & & 0 & 0 & $\operatorname{jan} / 01 / 197000: 00: 00$ & false & Open & Edit & Close \\
\hline ppp11 & any & & & default & & 0 & 0 & $\mathrm{jan} / 01 / 197000: 00: 00$ & false & Open & Edit & Close \\
\hline ppp12 & any & & & default & & 0 & 0 & $\mathrm{jan} / 01 / 1970$ 00:00:00 & false & Open & Edit & Close \\
\hline ppp13 & any & & & default & & 0 & 0 & $\mathrm{jan} / 01 / 197000: 00: 00$ & false & Open & Edit & Close \\
\hline ppp14 & any & & & default & & 0 & 0 & $\mathrm{jan} / 01 / 197000: 00: 00$ & false & Open & Edit & Close \\
\hline ppp15 & any & & & default & & 0 & 0 & jan/01/1970 00:00:00 & false & Open & Edit & Close \\
\hline ppp16 & any & & & default & & 0 & 0 & $\mathrm{jan} / 01 / 197000: 00: 00$ & false & Open & Edit & Close \\
\hline ppp17 & any & & & default & & 0 & 0 & jan/01/1970 00:00:00 & false & Open & Edit & Close \\
\hline ppp18 & any & & & default & & 0 & 0 & jan/01/1970 00:00:00 & false & Open & Edit & Close \\
\hline ppp19 & any & & & default & & 0 & 0 & jan/01/1970 00:00:00 & false & Open & Edit & Close \\
\hline ppp20 & any & & & default & & 0 & 0 & $\mathrm{jan} / 01 / 197000: 00: 00$ & false & Open & Edit & Close \\
\hline
\end{tabular}

Figure 8: System control interface

Table 1: Comparing the proposed monitoring system with other systems [20-22]

\begin{tabular}{|c|c|c|c|c|c|c|}
\hline & 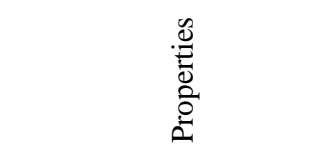 & 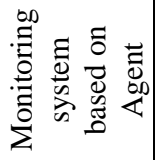 & $\begin{array}{l}\frac{0}{\tilde{E}} \\
\tilde{z} \\
\stackrel{\Xi}{E}\end{array}$ & 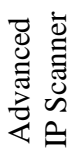 & 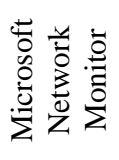 & $\begin{array}{l}\overrightarrow{3} \\
3 \\
3 \\
\frac{3}{0} \\
\text { in }\end{array}$ \\
\hline 1 & Web browser interface & 1 & 0 & 0 & 0 & 0 \\
\hline 2 & Remote control & 1 & 1 & 1 & 0 & 1 \\
\hline 3 & Speed & 1 & 1 & 1 & 1 & 1 \\
\hline 4 & Security service & 1 & 0 & 0 & 0 & 1 \\
\hline 5 & Control and management & 1 & 1 & 0 & 1 & 1 \\
\hline 6 & Agent -based & 1 & 1 & 0 & 0 & 0 \\
\hline 7 & Email alert & 1 & 0 & 0 & 0 & 0 \\
\hline 8 & $\begin{array}{l}\text { AVERAGE RESPONES } \\
\text { TIME }\end{array}$ & 1 & 1 & 1 & 1 & 0 \\
\hline 9 & Chatting & 0 & 0 & 0 & 0 & 0 \\
\hline 10 & Filter display data & 1 & 0 & 1 & 1 & 0 \\
\hline 11 & Filter web page & 1 & 1 & 1 & 1 & 0 \\
\hline 12 & Hardware monitor & 1 & 1 & 1 & 1 & 1 \\
\hline 13 & GUI & 1 & 1 & 1 & 1 & 1 \\
\hline
\end{tabular}




\begin{tabular}{|c|l|c|c|c|c|c|}
\hline 14 & Traffic monitor & 1 & 1 & 1 & 1 & 1 \\
\hline 15 & $\begin{array}{l}\text { Display voltage and health } \\
\text { devices }\end{array}$ & 1 & 1 & 0 & 0 & 1 \\
\hline 16 & Connect to database & 0 & 1 & 0 & 0 & 1 \\
\hline 17 & SMS alert & 0 & 0 & 0 & 0 & 1 \\
\hline 18 & Screen Alert & 0 & 1 & 1 & 1 & 1 \\
\hline 19 & Reliability & 1 & 1 & 1 & 1 & 1 \\
\hline 20 & System information & 1 & 0 & 0 & 0 & 1 \\
\hline \multicolumn{2}{|l|}{ Percentage of systems properties } & $80 \%$ & $65 \%$ & $50 \%$ & $50 \%$ & $65 \%$ \\
\hline
\end{tabular}

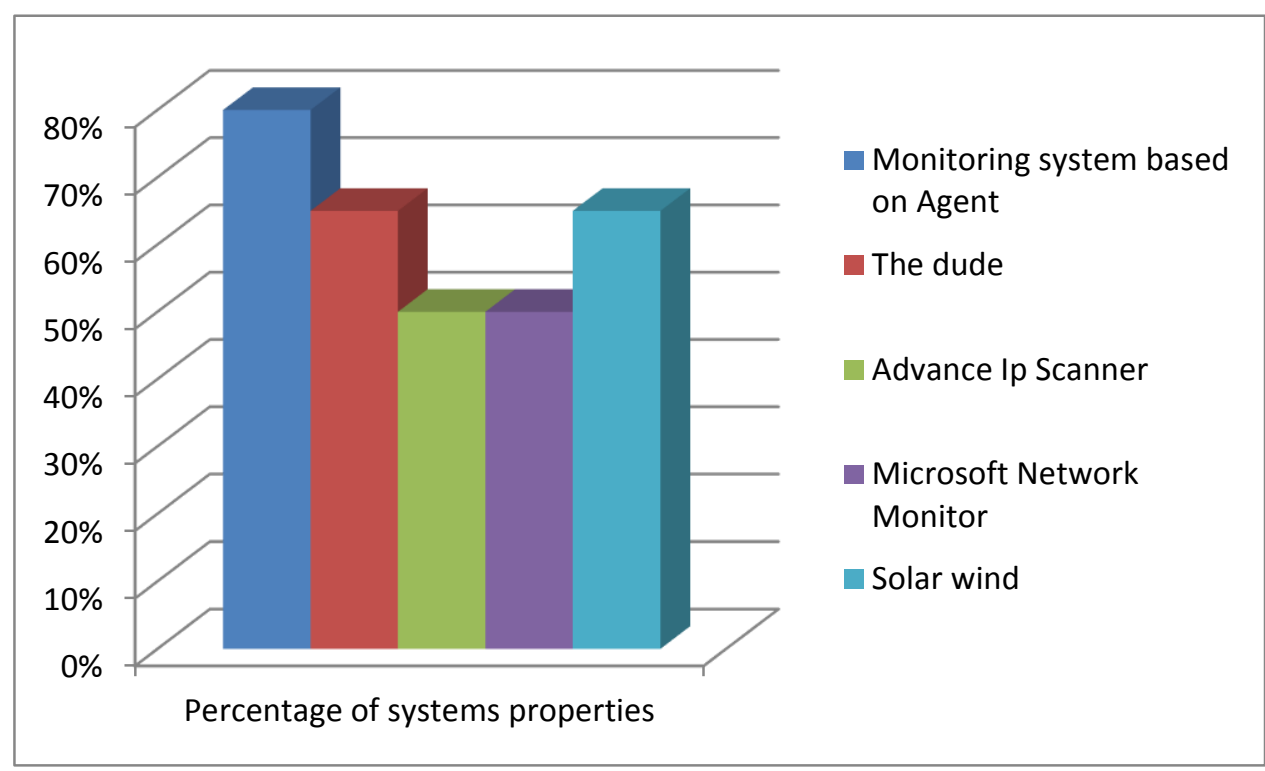

Figure 9: Comparing the proposed monitoring system with other systems

\section{REFERENCES}

[1] S. Mazaheri, "Network Monitoring System", MSc. Thesis, Computer Engineering, Eastern Mediterranean University, 2015.

[2] P. Bellavista; A. Corradi; and F. Tarantino, "Mobile Agents For WebBased Systems Management", Viale Risorgimento 2, 40136 Bologna, Italy, 1999

[3] S. Perera; W. Fonseka; I. Samaradiwakara; N. Withanage; and H. Wijekantha, "Web-Based Network Monitoring System", Sri Lanka Institute of Information Technology, 2014.

[4] B. Kurt; E. Zeydan; U. Yabas; I. Alper; K. Güne; K. Kurt and A. T. Cemgil, "Network Monitoring System for HighSpeed Network Traffic", Conference: 2016 13th Annual IEEE International Conference on Sensing, Communication, and Networking (SECON), Istanbul, Turkey June 2016.

[5] G. Pavlou; G. Mykoniatis; and J. Sanche, "Distributed Intelligent Monitoring and Reporting Facilities", Distributed Systems Engineering, Vol. 3, No. 2, pp. 124-135, 1996.

[6] S. Karanth and A. Tripathi, "Monitoring of Wireless Networks for Intrusions and Attacks", Department of Computer Science and Engineering University of Minnesota, February 24, 2004.

[7] H. B. Newman; I .C. Legrand; P. Galvez; R. Voicu; and C. Ciristoiu," A Distributed Monitoring Service Architecture", California Institute of Technology, 2003.

[8] H. B. Newman; I. C. Legrand; and P. Galvez, "Monalisa: A Distributed Monitoring Service Architecture", Califonia Institute of Technology, Pasadena, CA91125, USA, 2003. 
[9] M. Brockmeyer and J. Shamsi. Shamsi, "Principles of Network Monitoring", Department of Computer Science, Wayne State University 5143 Cass Avenue,431 State Hall, Detroit, MI 48202, USA, 2010.

[10] N. Blaauwbroeka, D. Kuikenb, P. Nguyena, H. Vedderb, and $M$. Roggenkampb, "Distribution Network Monitoring: Interaction Between EU Legal Conditions and State Estimation Accuracy", University of Groningen, Groningen, the Netherlands, 2018.

[11] A. Monasa; A. Vermaa; A. Gawaria; R. and S. Paswan, "Portable Network Monitor using ARM Processor", 2nd International Conference on Intelligent Computing, Communication \& Convergence, EL Sevier, 2016.

[12] Z. Chen, G. Xu, V. L. Mahalingam, J. Nguyen, W. Yu, and C. Lu, "Cloud Computing Based Network Monitoring and Threat Detection System for Critical Infrastructures", Department of Computer and Information Sciences, Towson University, 2016.

[13] Z. H. Tao, N. S. Liang, "Design Of Remote Monitoring System for Environmental Parameters Based on GPRS Technology", Microcomputer \& Its Applications, 2010.

[14] S. Gadge, and B. Amravati, "Intelligent Embedded System Based Remote Monitoring using Mobile", Semantic Scholar, Sant Gadge Baba Amravati University, Amravati, MS, India, 2012.

[15] S. Funfroken, "How to Integrate Mobile Agent into Web Server", Computer Science Published 1997 in Proceedings of IEEE 6th Workshop on Enabling Technologies, 18-20 June 1997.

[16] G. M. Noikova, and E. J. Azofeifa, "Domain-Theory Verification Using Multi-Agent System", Procedia Computer Science 103, ScienceDirect, pp.120 - 125, 2017.

[17] N. Jabeur, T. Al_Belushi, and M. Mbarki, "Toward Living Smart Logistics Collaboration With Multi-Agent System Based Solution", The 8th International Conference on Ambient Systems, Networks and Technologies, Science Direct, Procedia Computer Science 109C, pp. 672-679, 2017.

[18] Haihong Gao; A. Jasti; R. Pendse, "An Intelligent Network Monitoring And
Management Tool For Aircraft Data Networks", Ieee Xplore, 2005.

[19] M. Achour, F. Betz, A. Dovgal, And N. Lopes, "Php Manual", Peter Cowburn Available at https://Www.Php.Net/Manual/En/IntroWhatis.Php, 2020.

[20] S. Suri, and V. Batra, "Comparative Study of Network Monitoring Tools", International Journal of Innovative Technology and Exploring Engineering, Vol. 1, No. 3, pp. 63-65, 2010.

[21] SolarWinds, "Network Performance Monitor", Available at https://www.solarwinds.com/networkperformance-monitor?CMP=BIZ-TADPCWDLD-NPM_PP-NPM-PP-Q116, 2020.

[22] J. O. Adetokunbo; O. Clement; and O. Emmanuel, "An Enhanced Network Monitoring System using Multi-Agent based Technology", International Journal of Advanced Research in Computer and Communication Engineering, Vol. 6, Issue 5, pp. 1-8, 2017. 


\section{تصميم نظام فعال لمراقبة الشبكة بالاعتماد على الوكيل}

توركان احمد خليل

turkan@uomosul.edu.iq
* (حمد محمد بشير

ahmed.basheer@uoninevah.edu.iq

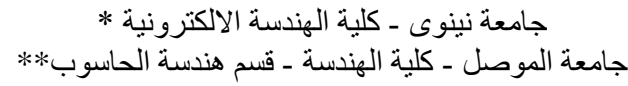

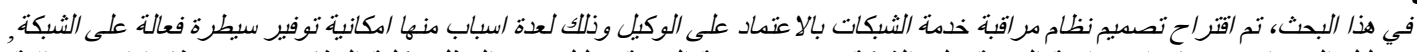

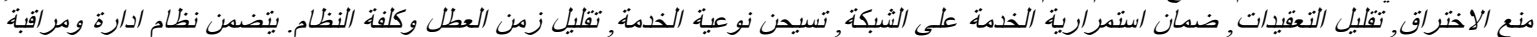

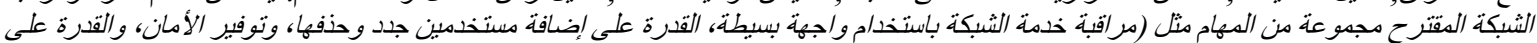

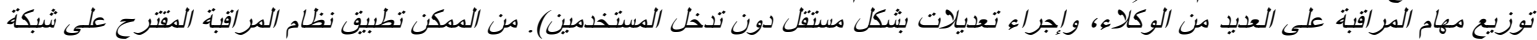

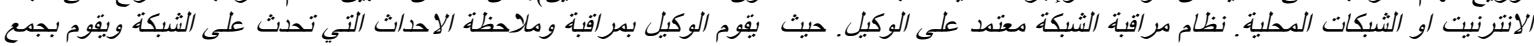

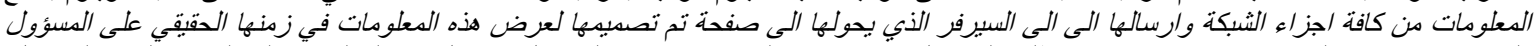

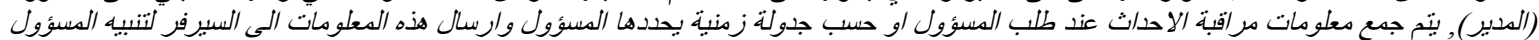

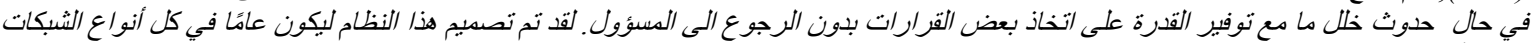

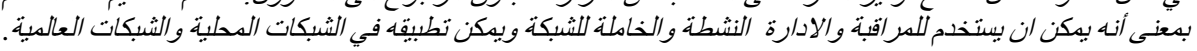

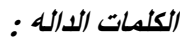

العبل ، نظام المراقبة , خدمة الشبكات, ادارة الشبكة. 